\title{
PHYTOCHEMICAL STUDY OF ENDEMIC SPECIES HELLEBORUS CAUCASICUS, HELLEBORUS ABCHASICUS AND FICARIA POPOVII SPREAD IN SOUTHERN COLCHIS
}

\author{
Medea Beridze $^{1}$, Aleko Kalandia ${ }^{2}$, Indira Japaridze ${ }^{3}$, Maia Vanidze ${ }^{4}$, \\ Natela Varshanidze $^{5}$, Nazi Turmanidze ${ }^{6}$, Ketevan Dolidze ${ }^{7}$, Inga Diasamidze ${ }^{8}$, \\ Eteri Jakeli ${ }^{9}$
}

\begin{abstract}
There are 176 endemic plants spread in southern Colchis, of which 45 can be used for some medical treatments. The bioecology and detailed phytochemical content of some medicinal plant populations have not been studied so far.

The research objectiveis to study the phytochemical content of endemic species of Helleborus caucasicus, Helleborus abchasicus and Ficaria popovii spread in southern Colchis.

The research method for the phytochemical content included separation analysis, whichwas performed byusing UPLC-MS (Waters Acquity QDa detector).

Three Steroidal glycosideswere isolated from the $\mathrm{MeOH}$ extract of the plants of Helleborus caucasicus and Helleborus abchasicus: Hellebrigenin-D-glucose, 20 - Hydroxyecdysone and Hydroxyecdysone - 3 glucoside. Two saponins (Hederagenin 3-O - $\alpha$-L-arabino pyranoside, Hederagenin 28-O-[ $\alpha$-L-rhamno-pyranosyl $(1 \rightarrow 4)-\beta$-D-glucopyranosyl- $(1 \rightarrow 6)] \beta-$ D-lucopyranoside) and four flavonoids (kaempferol 3-O- $\beta$-D- (6"- $\alpha$-L-rhamnopyranosyl)-glucopyranoside (nicotiflorin), apigenin 8-C- $\beta$-D-glucopyranoside (vitexin), luteolin 8-C- $\beta$-D-glucopyranoside (orientin), quercetin 3-O-rutinoside) were isolated from the tubers and flowers of Ficaria Popovii.

Three Steroidal glycosides and Hydroxyecdysone -3 glucoside were isolated from the MeOH extract of Helleborus caucasicus.In addition, two saponins and four flavonoids were isolated from the tubers and leaves of FicariaPopovii.
\end{abstract}

UDC Classification: 577, DOI: https://doi.org/10.12955/pmp.v1.89

Keywords:Phytochemistry, UPLC-MS,Ficaria Popovii, Helleborus caucasicus, Helleborus abchasicus

\section{Introduction}

The floristic region of South Kolkheti (Adjara) isthe part of the Caucasus Ecoregion, which is includedamong the 200 world-renowned ecoregions by the World Wildlife Fund (WWF). These ecoregions are characterized by plant diversity, high levels of endemism, taxonomic uniqueness and rarity of biomes globally (IUCN. 2006).

Southern Kolkheti (Adjara), in the Caucasus ecoregion, is characterized by the special diversity and originality of the flora, which is present due to the flora complexes rich in plant clusters and relict, and endemic species formed in the third period(Manvelidze et al., 2010).

1837 species of plants are common in southern Colchis, including 176 endemic ones (Varshanidze et al., 2018).Among the endemics, the following genera are distinguished by their decorative and medicinal properties: Helleborus and Ficaria, bothspecies of genusflower in winter-early spring. (Memiadze, 2004).

\footnotetext{
${ }^{1}$ Batumi Shota Rustaveli State University, Faculty of Natural Sciences and Health Care, Department of Biology, Batumi, Georgia, medeaberidze89@mail.ru

${ }^{2}$ Batumi Shota Rustaveli State University, Faculty of Natural Sciences and Health Care, Department of chemistry, Batumi, Georgia,a.kalandia@bsu.edu.ge

${ }^{3}$ Batumi Shota Rustaveli State University, Faculty of Natural Sciences and Health Care, Department of chemistry, Batumi, Georgia,indira.djafaridze@bsu.edu.ge

${ }^{4}$ Batumi Shota Rustaveli State University, Faculty of Natural Sciences and Health Care, Department of chemistry, Batumi, Georgia, maia.vanidze@bsu.edu.ge

${ }^{5}$ Batumi Shota Rustaveli State University, Faculty of Natural Sciences and Health Care, Department of Biology, Batumi, Georgia, natela.varshanidze@gmail.com

${ }^{6}$ Batumi Shota Rustaveli State University, Faculty of Natural Sciences and Health Care, Department of Biology, Batumi, Georgia,turmanidze.nazi@bsu.edu.ge

${ }^{7}$ Batumi Shota Rustaveli State University, Faculty of Natural Sciences and Health Care, Department of Biology, Batumi, Georgia, diasamidze.inga @bsu.edu.ge

${ }^{8}$ Batumi Shota Rustaveli State University, Faculty of Natural Sciences and Health Care, Department of Biology, Batumi, Georgia, ketodolidze@yahoo.com

${ }^{9}$ Batumi Shota Rustaveli State University, Faculty of Natural Sciences and Health Care, Department of Pharmacy, Batumi, Georgia, eteri_jakeli@yahoo.com
} 
The genus Helleborus is represented by 2 species: Helleborus caucasicus and Helleborus abchasicus. Furthermore, the genus Ficaria is represented by 1 species -Ficaria popovii.(Dmitrieva, 1990).

Helleborus caucasicusandHelleborus abchasicus(Ranunculaceae) are evergreen, blooming in autumnwinter-spring seasons, rooted, herbaceous plants, growing on cliffs. Their vegetation begins at the end of November, blooming starts in December, and fruiting is in progress in March-April. Ficaria popovii (Ranunculaceae) is endemic of the narrow-local ephemeroid nature of Adjara.Its vegetation begins in November, blooms in January-February, fruiting is in progress in March-April, and dries in early May.Among these species, Helleborus caucasicus and Helleborus Abchasicus are widely distributed. Helleboruscaucasicus is an important source of chemical compounds with a great medical potential for the treatment of some serious diseases such as cancer, ulcers, diabetes, as well as some medical problems such as toothache, eczema, low immunity and arthritis. Ficaria popovii tubers and leaf extracts are used as a diuretic, blood purifier and wound healer, as well as in salads made from leaves that cleanse the blood of pathogenic microbes (Jakeli et al. 2018).

It is the first time that wehave studied the detailed phytochemical content of Ficaria popovii tubers and leaves,and Helleborus caucasicus and Helleborus abchasicus rootstocks in southern Colchis.

\section{Methods and materials}

Plant material: the leaves, tubers and rhizomes of three species-Helleborus caucasicus $H$.

Abchasicus,Ficaria popoviithat were collected in Adjara(Tab. 1).

\begin{tabular}{|l|l|l|l|l|}
\hline \multicolumn{5}{|l|}{ Table 1: Information about test samples } \\
\hline \multirow{5}{*}{} & $\#$ & Test species & Samples collected area & Samples data \\
\cline { 2 - 5 } & $\mathbf{1}$ & Helleborus caucasicus & v. 1 Maisi, Adjara & February 2020 \\
\cline { 2 - 4 } & $\mathbf{2}$ & Helleborus abchasicus & s.Kutaisi, Imereti & February 2020 \\
\cline { 2 - 4 } & $\mathbf{3}$ & Ficaria popovii & v. Tsikhisdziri, Adjara & March 2020 \\
\hline Source: Authors
\end{tabular}

Ultra Performance Liquid Chromatography (UPLC)- Preparation of a sample for chromatographic examination of saponins: Various parts of the plant Ficaria popovii were taken for analysis - Flower, leaves and tubers, and the rhizomes and leaves of Helleborus caucasicus and Helleborus abchasicusas well. Raw material of the sample was taken for analysis, Extraction of the crushed sample $(2.5 \mathrm{~g})$ was performed with methanol $(100 \% 50-50 \mathrm{ml})$ three times in an ultrasound bath.The next step intended to filter the extracts by using a vacuum pump.We concentrated methanolic extracts at a temperature of $400^{\circ} \mathrm{C}$ under vacuum conditions until there was an aqueous residue.(In the case of concentrated leaf extract, the sample was further treated with chloroform to remove chlorophyll green pigments).In order to elute and concentrate saponins, we divided the concentrated water fraction by C18.In the initial stage, the sorbent was conditioned, in particular, the sorbent was activatedwith methanol and balancedby using water.In the first stage after sampling, we removed unwanted components with water.In the final stage, the research components wereeluted with methanol (100\%). The resulting eluent waslater concentrated to a dry mass.For chromatographic analysis, dry mass extraction was performed by using the mobile phase (acetonitrile: a mixture of methanol).The sample for chromatography was filtered into a $0.45 \mu \mathrm{m}$ filter.

The flavonoids were tentatively identified according to their retention time (Rt), the wavelength of maximum absorbance $(\lambda \max )$, pseudomolecular ion $([\mathrm{M}-\mathrm{H}]-)$ and compounds mass database METLIN (https://metlin.scripps.edu).

Concentration of analytical samples:Ficaria popovii - flower - g/200 $\mu \mathrm{l}(2.5 \mathrm{~g} / 500 \mu \mathrm{l})$, leaves - g/25 $\mu \mathrm{l}$ $(20 \mathrm{~g} / 500 \mu \mathrm{l})$ and tubers $-\mathrm{g} / 50 \mu \mathrm{l}(10 \mathrm{~g} / 500 \mu \mathrm{l})$.Helleborus caucasicus rhizomes - $\mathrm{g} / 80 \mu \mathrm{l}(15 \mathrm{~g} / 1200$ $\mu \mathrm{l})$ and leaves - $\mathrm{g} / 4 \mathrm{ml}(15 \mathrm{~g} / 60 \mathrm{ml})$. and Helleborus abchasicus rootstock - $\mathrm{g} / 200 \mu \mathrm{l}(10 \mathrm{~g} / 2000 \mu \mathrm{l})$ and leaves - $\mathrm{g} / 4 \mathrm{ml}(10 \mathrm{~g} / 40 \mathrm{ml})$.

\section{Results and discussion}

The detected flavonoids of Ficaria popovii are presented in Table 2. Four flavonoids were found, the UPLC - flavonoids profile of the ethanolic extract of the sample Tuber (The substance 1, 2, 3 and 4) and flower (The substance 1 and 2) of Ficaria popovii). Flavonoids Composition of Ficaria popovii tubers and leaves. 


\begin{tabular}{|c|c|c|c|c|}
\hline Species name:Ficaria popovii & $\mathbf{m} / \mathbf{z}$ & $\begin{array}{l}\text { Retention } \\
\text { Time }\end{array}$ & leaves & tubers \\
\hline \multicolumn{5}{|c|}{ flavonoids } \\
\hline quercetin 3-O-rutinoside(rutin) & 609 [M-H]- & 5.653 & + & + \\
\hline $\begin{array}{l}\text { kaempferol 3-O- } \beta \text {-D- (6"- } \alpha \text {-L-rhamnopyranosyl)- } \\
\text { glucopyranoside (nicotiflorin) }\end{array}$ & $593[\mathrm{M}-\mathrm{H}]-$ & 6.237 & + & + \\
\hline luteolin 8-C- $\beta$-D-glucopyranoside (orientin) & $447[\mathrm{M}-\mathrm{H}]-$ & 7.119 & & + \\
\hline apigenin $8-C-\beta$-D-glucopyranoside (vitexin) & $431[\mathrm{M}-\mathrm{H}]-$ & 10.339 & & + \\
\hline
\end{tabular}
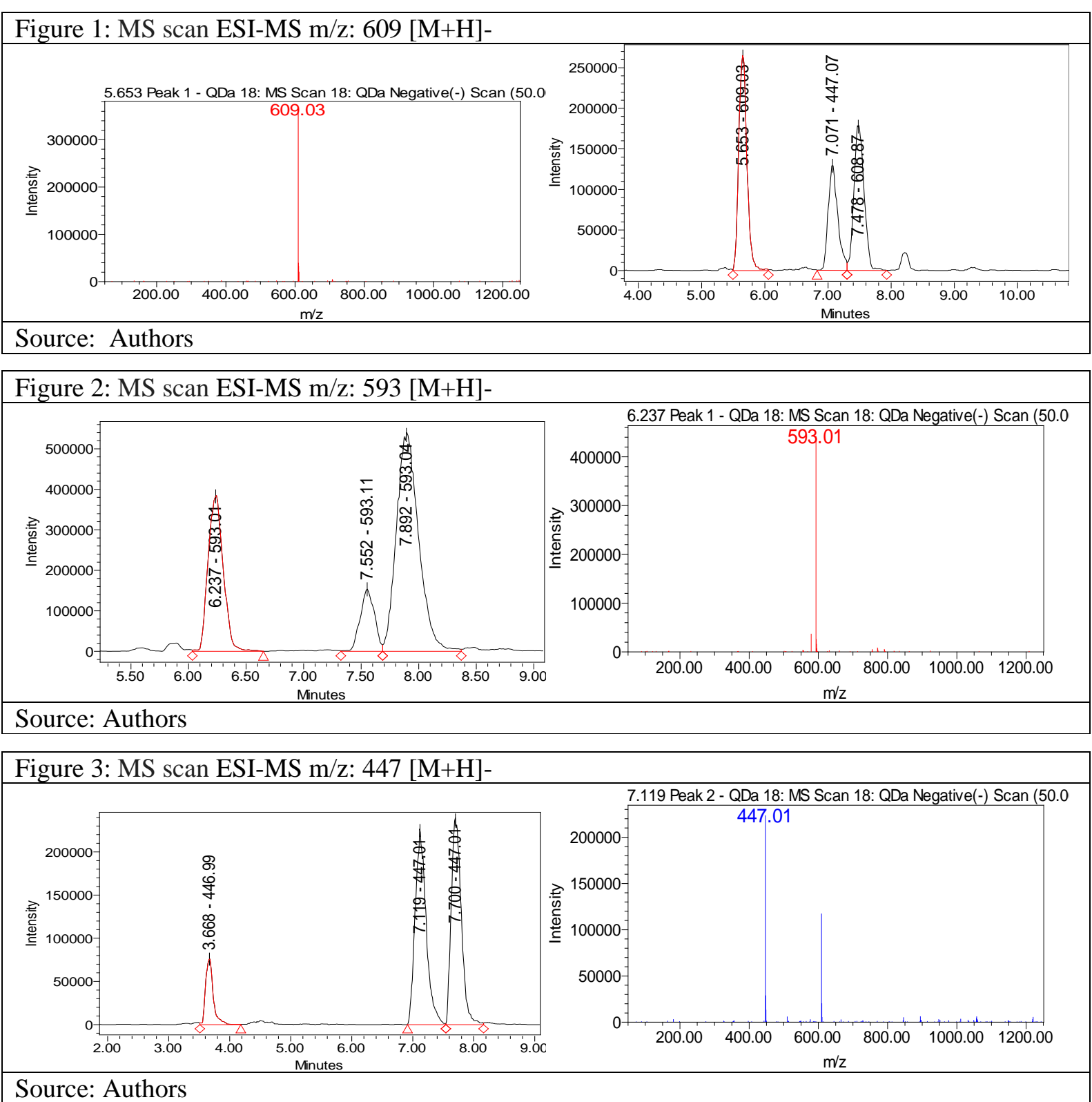

Substance 1 - (Fig.1) retention time is $5.653 \mathrm{~min}, \Lambda \max 254$ and $354 \mathrm{~nm}$ (Table 2); according to the obtained results and compounds mass database METLIN (https://metlin.scripps.edu) substance 1 is quercetin 3-O-rutinoside(rutin) $\mathrm{C} 27 \mathrm{H} 30 \mathrm{O} 16$, MW 610,15;

Substance 2 - (Fig.2) retention time is $6.237 \mathrm{~min}, \Lambda \max 266$ and $346 \mathrm{~nm}$ (Table 2); according to the obtained results and compounds mass database METLIN, substance 2 is kaempferol 3-O- $\beta$-D- (6"$\alpha$-L-rhamnopyranosyl)- glucopyranoside (nicotiflorin) C27H30O15,MW 594.15 
Substance 3 - (Fig.3) retention time is $7.071 \mathrm{~min}, \widehat{K} \max 254$ and $267 \mathrm{~nm}$ (Table 2); according to the obtained results and compounds mass database METLIN, substance 3 is luteolin 8 -C- $\beta$-Dglucopyranoside (orientin) C21H20O11, MW 448.1;

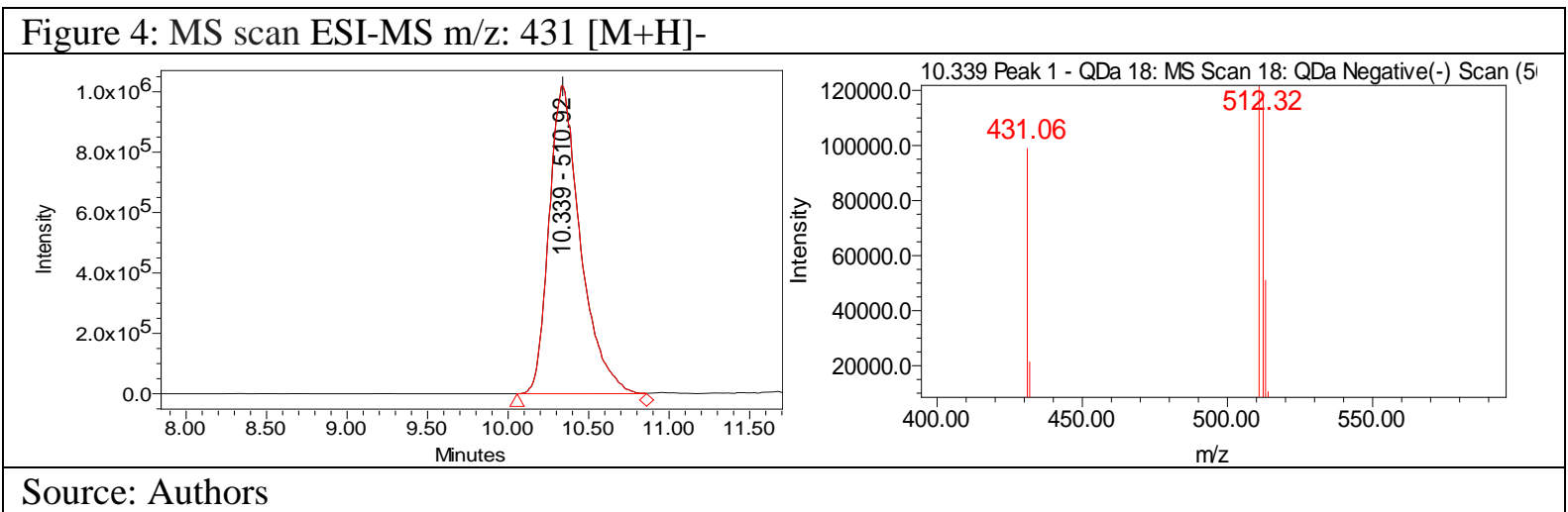

Substance 4 - (Fig.4) retention time is $10.339 \mathrm{~min}, K \max 268$ and $334 \mathrm{~nm}$ (Table 2); according to the obtained results and compounds mass database METLIN, substance 4 is apigenin $8-\mathrm{C}-\beta$-Dglucopyranoside (vitexin) C21H20O10, MW 432.105;

Two known saponins, glycosides of oleanolic acid, have been isolated from the tubers of Ranunculus ficaria PopoviiL. (Ranunculaceae): 28-Glucosyloleanolic acid 3-arabinoside and 28-[Glucosyl-(1->6)glucosyl]oleanolic acid 3-arabinoside.

\begin{tabular}{|c|c|c|c|}
\hline \multicolumn{4}{|c|}{ Table 3: Saponins composition of Ficaria popovii tubers } \\
\hline$\#$ & Species name:Ficaria popovii & \multicolumn{2}{l|}{ Saponin } \\
\hline & \multicolumn{2}{|l|}{ Tubers } & ESI-MS m/z \\
\hline $\mathbf{1}$ & $\begin{array}{c}\text { Mss } \\
\text { 3-arabinoside } \\
\text { C41H66O12 }\end{array}$ & 912.50 & $769.45[\mathrm{M}+\mathrm{F}]$ \\
\hline $\mathbf{2}$ & $\begin{array}{c}\text { 28-[Glucosyl-(1->6)-glucosyl]oleanolic acid } \\
\text { 3-arabinosideC47H76O17 }\end{array}$ & 750.45 & $971.52[\mathrm{M}+\mathrm{CH} 3 \mathrm{COO}]$ \\
\hline
\end{tabular}

Source: Authors

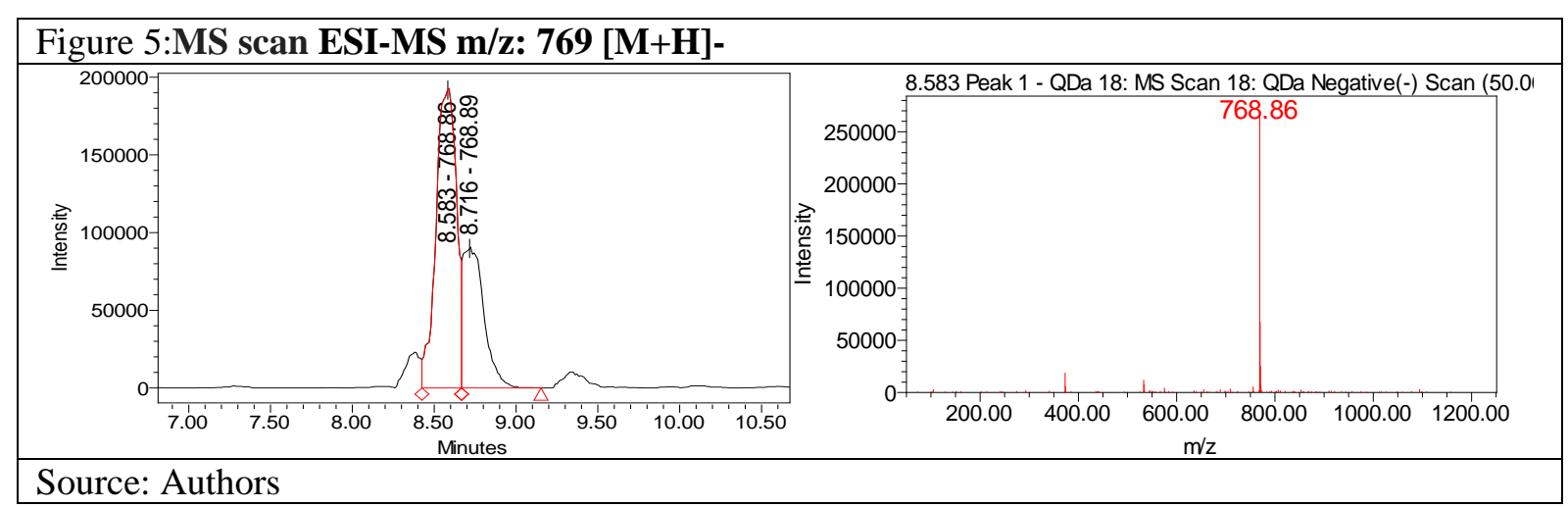

Substance 5 - (Fig.5) retention time is $8.583 \mathrm{~min}$, (Table 3); according to the obtained results and compounds mass database METLIN (https://metlin.scripps.edu), substance 5 is 28Glucosyloleanolic acid 3-arabinoside. C41H66O12 MW 912.50; ESI-MS m/z [M+F];

Substance 6 - (Fig.6) retention time is $14.226 \mathrm{~min}$, (Table 3); according to the obtained results and compounds mass database METLIN (https://metlin.scripps.edu), substance 6 is 28 -[Glucosyl-(1>6)-glucosyl] oleanolic acid 3-arabinoside C47H76O17 MW 750.45; ESI-MS m/z 971.52 $[\mathrm{M}+\mathrm{CH} 3 \mathrm{COO}]$

Using UPLC-MS / MS, 4 flavonoids and 2 saponins have been identified in the plant Ficaria popovii extract. In particular, in leaves identified 2 substances (quercetin 3-O-rutinoside and kaempferol 3-O$\beta$-D- (6"- $\alpha$---rhamnopyranosyl) - glucopyranoside), and in tubers 4 flavonoids (quercetin 3-Orutinoside, kaempferol). 3-O- $\beta$-D- (6"- $\alpha$-L-rhamnopyranosyl) - glucopyranoside, luteolin 8 -C- $\beta$-D- 
glucopyranoside and apigenin 8-C- $\beta$-D-glucopyranoside). 3-arabinoside and 28- [Glucosyl- (1-> 6) glucosyl] oleanolic acid 3-arabinoside.These are the first studies of the Ficaria popoviiflavonoid complex and saponins using UPLC-MS / MS.

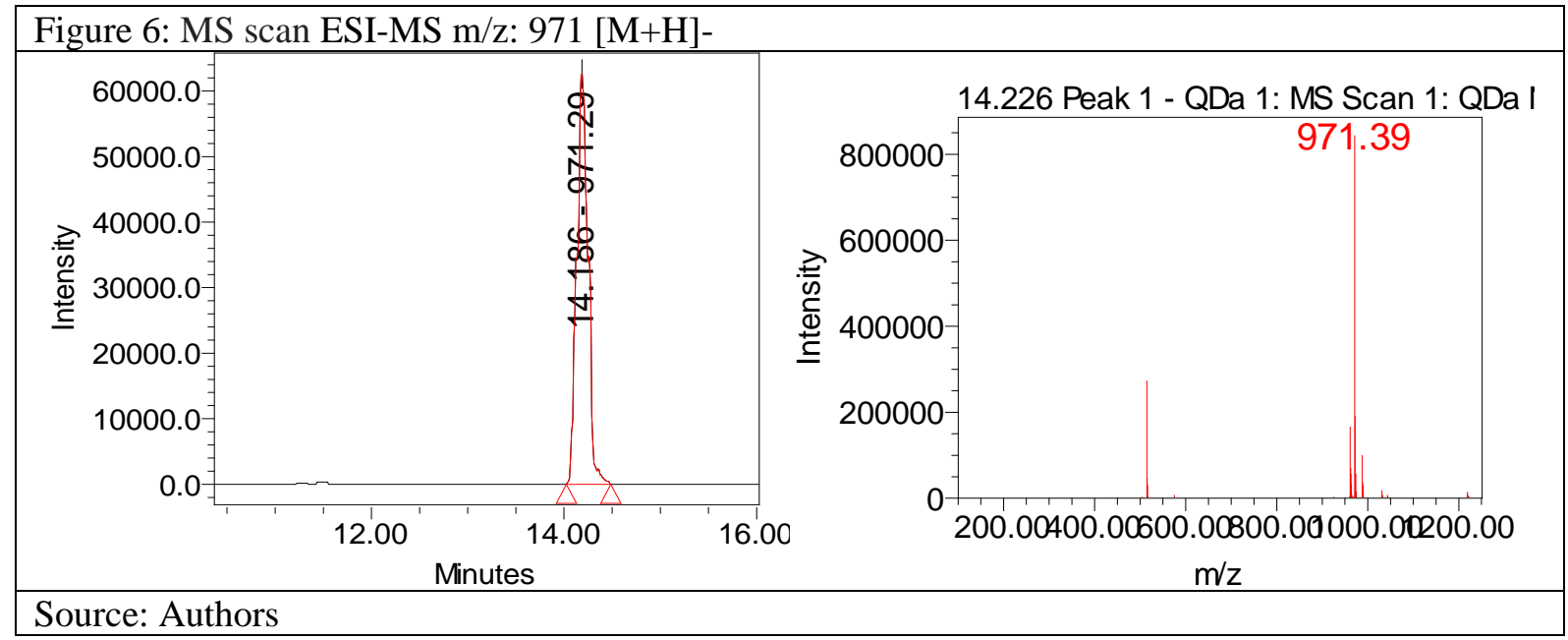

\begin{tabular}{|c|c|c|c|c|c|c|c|}
\hline \multirow[t]{2}{*}{ \# } & \multicolumn{3}{|c|}{$\begin{array}{c}\text { Species name: } \\
\text { Heleborus caucasicus, Helleborus abchasicus }\end{array}$} & \multicolumn{2}{|c|}{$\begin{array}{c}\text { Heleborus } \\
\text { Caucasicus }\end{array}$} & \multicolumn{2}{|c|}{$\begin{array}{c}\text { Heleborus } \\
\text { abchasicus }\end{array}$} \\
\hline & & Mass & ESI-MS m/z & Tubers & Flowers & Tubers & Flowers \\
\hline 1 & $\begin{array}{l}20 \text { - Hydroxyecdysone } \\
\text { (Ecdysterone)C27H44O7 }\end{array}$ & 480.3087 & & + & + & + & + \\
\hline 2 & Bufadienolide $\mathrm{C} 24 \mathrm{H} 34 \mathrm{O} 2$ & 354.2558 & $\begin{array}{c}503.2[\mathrm{M} \\
+\mathrm{Na}]+ \\
\end{array}$ & + & & + & \\
\hline 3 & Furostan $\mathrm{C} 27 \mathrm{H} 46 \mathrm{O}$ & 386.3548 & $\begin{array}{c}355.2[\mathrm{M}+ \\
\mathrm{H}]+\end{array}$ & + & + & + & + \\
\hline 4 & $\begin{array}{l}\text { Hellebrigenin-D- } \\
\text { glucoseC } 30 \mathrm{H} 42 \mathrm{O} 11\end{array}$ & 578.2726 & $\begin{array}{c}431.32 \\
{[\mathrm{M}+2 \mathrm{Na}-\mathrm{H}]+}\end{array}$ & + & & + & \\
\hline
\end{tabular}

Source: Authors

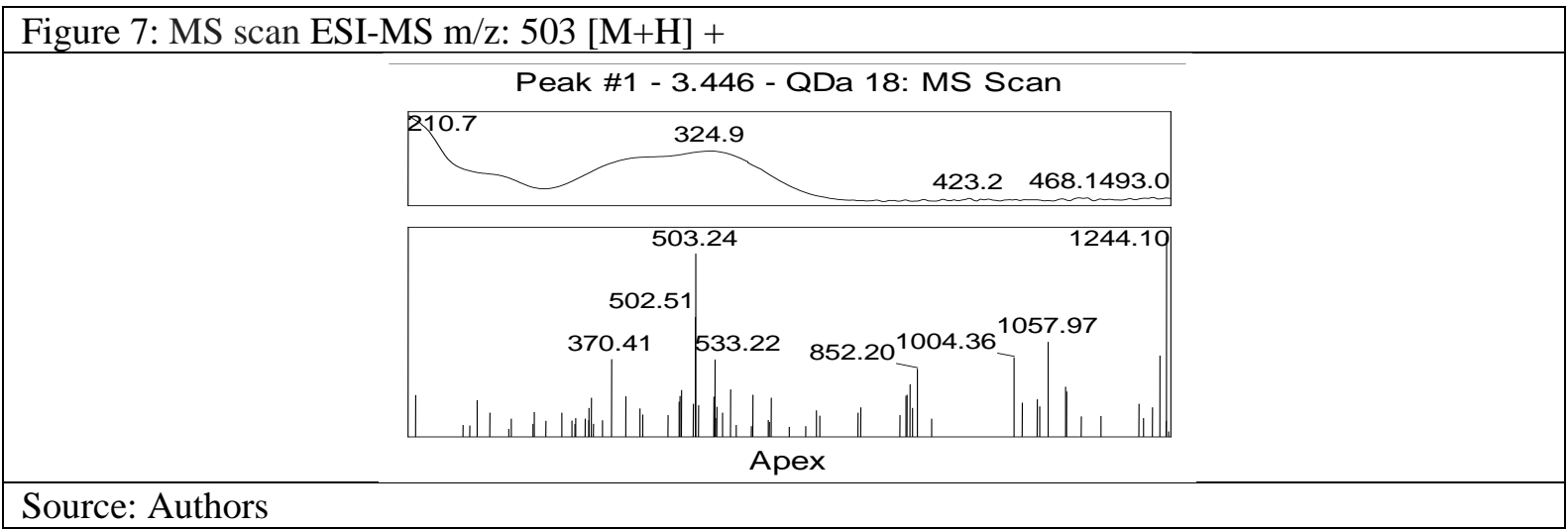

Four steroidal compounds, were isolated from the $\mathrm{MeOH}$ extract (the tubers and leaves ) of Helleborus caucasicus and Helleborusabchasicus: 20- Hydroxyecdysone (Ecdysterone), Bufadienolide, Furostan and Hellebrigenin-D-glucose. All four substances are identified in the extract of the rhizomes, while in the flowers2 - Ecdysterone and Furostan.

Substance 7 - (Fig. 7) retention time is $3.446 \mathrm{~min}, \quad \kappa \max 324 \mathrm{~nm}$ (Table 4); In positive ionization mode, substance 7 mainly showed molecular ions ESI-MS m/z: $503.2[\mathrm{M}+\mathrm{Na}]+$; according to the obtained results and compounds mass database METLIN (https://metlin.scripps.edu), substance 7 was identified as 20- Hydroxyecdysone (Ecdysterone);

Substance 8 - (Fig. 8) retention time is $5.407 \mathrm{~min}, K \max 313.7 \mathrm{~nm}$ (Table 4); In positive ionization mode, substance 8 mainly showed molecular ions ESI-MS m/z: $355.26[\mathrm{M}+\mathrm{H}]+$; according to the 
obtained results and compounds mass database METLIN (https://metlin.scripps.edu), substance 8 was identified as - Bufadienolide
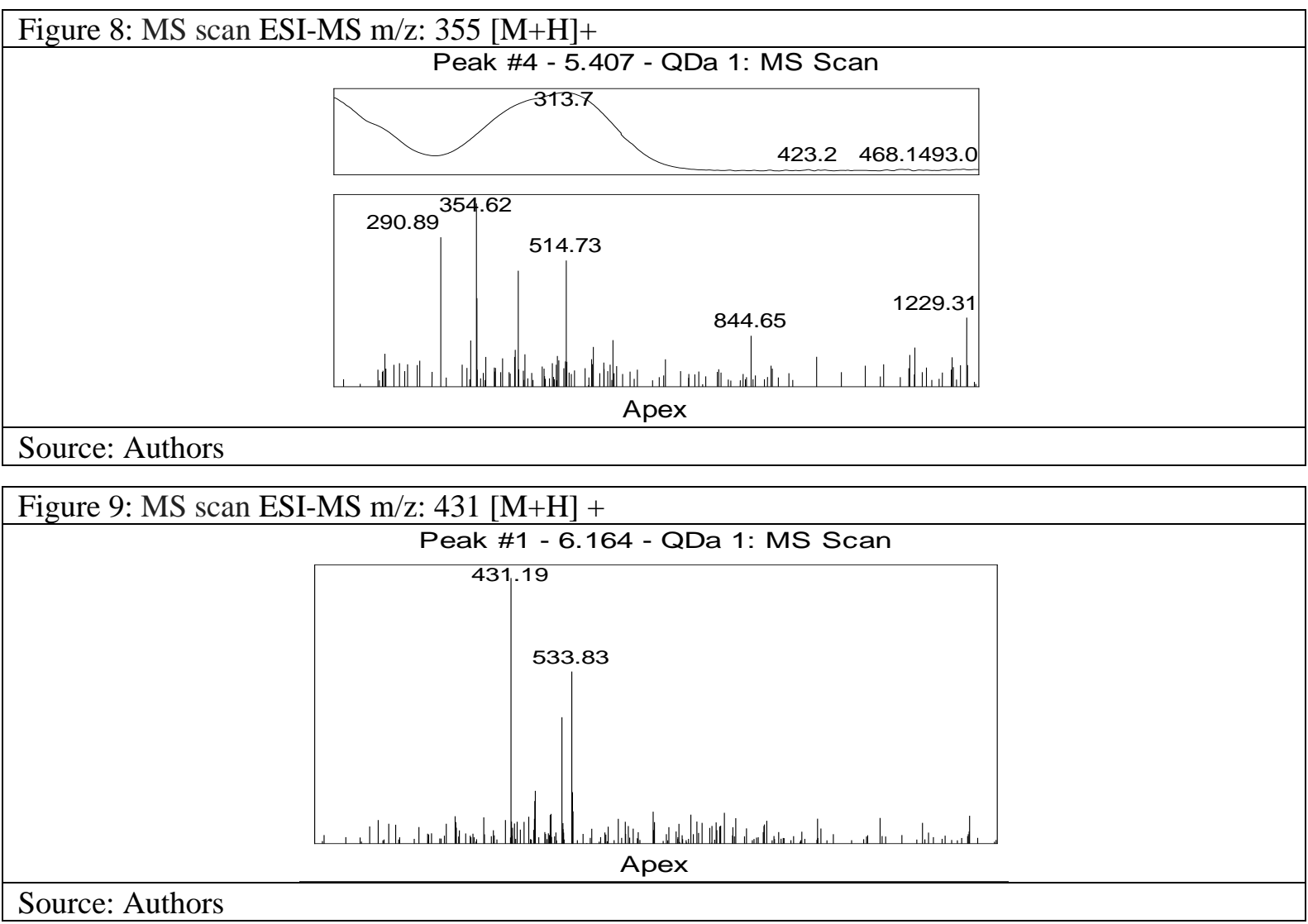

Substance 9 - (Fig.9) retention time is $6.164 \mathrm{~min}$; In positive ionization mode, substance 9 mainly showed molecular ions ESI-MS m/z: $431.32[\mathrm{M}+2 \mathrm{Na}-\mathrm{H}]+$; according to the obtained results and compounds mass database METLIN (https://metlin.scripps.edu), substance 9 was identified as Furostan

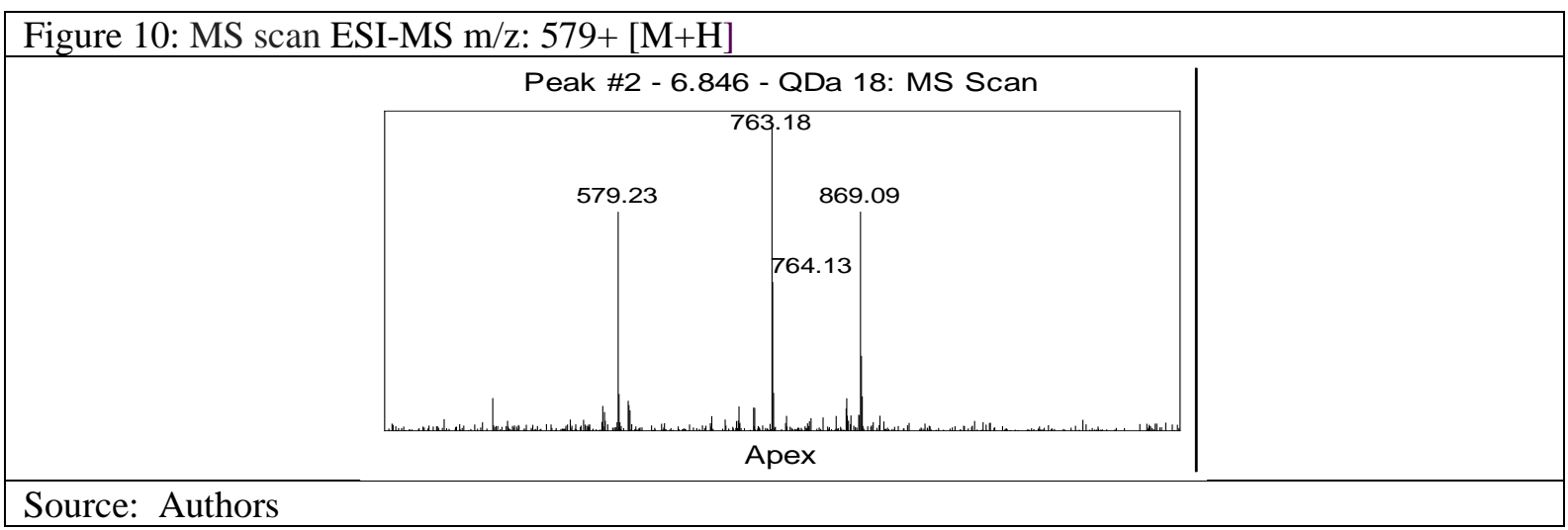

Substance 10 - (Fig.10) retention time is $6.164 \mathrm{~min}$; In positive ionization mode, substance 10 mainly showed molecular ions ESI-MS m/z: 579+ $[\mathrm{M}+\mathrm{H}]+$; according to the obtained results and compounds mass database METLIN (https://metlin.scripps.edu), substance 10 was identified as Hellebrigenin-Dglucose.

Four steroidal compounds, were isolated from the $\mathrm{MeOH}$ extract of Helleborus caucasicus and Helleborus abchasicus: 20- Hydroxyecdysone (Ecdysterone), Bufadienolide, Furostan and Hellebrigenin-D-glucose(Table 4). All four substances are identified in the extract of the rhizomes, while in the flowers2 - Ecdysterone and Furostan.

Using UPLC-MS / MS, the steroid composition of the plant Helleborus caucasicus and Helleborus abchasicus was studied. In particular, 4 substances were identified, 2 of which are found in leaves - 
Ecdysterone and Furostan, and 4 in tubers - Ecdysterone, Bufadienolide, Furostan and HellebrigeninD-glucose. Based on the obtained results, it can be concluded that the steroid composition of leaves and tubers of Helleborus caucasicus and Helleborus abchasicus is similar.

\section{Conclusion}

Vegetation of Helleborus caucasicus and Helleborus abchasicus begins at the end of November, blooming starts In December, and fruiting is in progress in March-April. Ficaria popovii (Ranunculaceae) blooms in January-February, fruiting is in progress in March-April, and dries in early May.

Three Steroidal glycosides were isolated from the $\mathrm{MeOH}$ extract of the plants of Helleborus caucasicus and Helleborus abchasicus- Hellebrigenin-D-glucose, 20 - Hydroxyecdysone and Hydroxyecdysone - 3 glucoside. Two saponins (Hederagenin 3-O - $\alpha$-L-arabino pyranoside, Hederagenin 28 -O-[ $\alpha$-L-rhamno-pyranosyl $(1 \rightarrow 4)-\beta$-D-glucopyranosyl- $(1 \rightarrow 6)] \beta$-D-lucopyranoside) and four flavonoids (kaempferol 3-O- $\beta$-D- (6"- $\alpha$-L-rhamnopyranosyl)-glucopyranoside (nicotiflorin), apigenin 8-C- $\beta$-D-glucopyranoside (vitexin), luteolin 8-C- $\beta$-D-glucopyranoside (orientin), quercetin 3O-rutinoside) have been isolated from the tubers and flowers of Ficaria Popovii.

On the basis of the conducted analysis,it is possible to make a conclusion that three Steroidal glycosides were isolated from the $\mathrm{MeOH}$ extract of the plants of Helleborus caucasicus and Helleborus abchasicus- Hellebrigenin-D-glucose, 20 - Hydroxyecdysone and Hydroxyecdysone - 3 glucosides. While, two saponins and four flavonoids were isolated from the tubers and flowers of Ficaria Popovii.

Steroidal glycosides, saponinsand flavonoids, that contribute to the biological activity of the plants, were identified in the leaves and tubers of Ficaria Popovii, Helleborus caucasicus and Helleborus abchasicus.

\section{References}

Dmitrieva, A. (1990). [in Russian], Key to flora of Adjara. Vol. II. Tbilisi: Metsniereba.

IUCN. (2006). Guidelines for using the IUCN Red List categories and criteria. Version 6.2. Retrieved from www.redlist.org/info/categories criteria.html.

Jakeli, E., Varshanidze, N., Diasamidze I., Dolidze K., Zarnadze N. (2018). Biodiversity of medical plants of wild flora in Ajara-South Colchis and their usage in folk medicine. 3-rd International Science Symposium "New Horizons in Science", Proceeding Book., At Pristina, Cosovo. 80-96.

Ladislav, N., Ghuloom, H., Al-Hasawi N. (2019). Structural Features and Biological Activities of Bufadienolides. Department of Pharmaceutical Chemistry, Faculty of Pharmacy, Kuwait University.

Manvelidze, Z., Memiadze, N., Kharazishvili, D., Varshanidze N. (2010). Diversity of floral area of Adjara. (List of wild grown plants species). Annalis of Agrarian science, 6 (2), 91-93.

Memiadze, N. (2004). Botanical and geographical survey of the endemics of Ajara-Lazeti flora. Bull. Georg. Acad. Sci. 169 (2), 341-343.

METLIN (2018). A Technology Platform for Identifying Knowns and Unknowns. Retrieved from https://metlin.scripps.edu. Tomczyk, M., Gude, J., Sochacki, M. (2002). Zeitschrift fur Naturforschung Flavonoids from Ficaria verna Huds. C, Journal of Biosciences, 57(5-6):440-444 DOI: 10.1515/znc-2002-5-606 PMID: 12132681.

Varshanidze, N., Turmanidze, N., Dolidze, K., Zarnadze, N., Diasamidze, I., Epitashvili, T., Katcharava, T. (2018).

Biodiversity of Medicinal Plants Containing Essential Oil and Their Spreading in Adjara. Universal Journal of Agricultural Research 6(3), 99-104 https://doi.org/10.13189/ujar.2018.060301. 